\title{
Papers
}

\section{Oral mucolytic drugs for exacerbations of chronic obstructive pulmonary disease: systematic review}

\author{
Phillippa J Poole, Peter N Black
}

\begin{abstract}
Objective To assess the effects of oral mucolytics in adults with stable chronic bronchitis and chronic obstructive pulmonary disease.

Design Systematic review of randomised controlled trials that compared at least two months of regular oral mucolytic drugs with placebo.

Studies Twenty three randomised controlled trials in outpatients in Europe and United States.

Main outcome measures Exacerbations, days of illness, lung function, adverse events.

Results Compared with placebo, the number of exacerbations was significantly reduced in subjects taking oral mucolytics (weighted mean difference -0.07 per month, $95 \%$ confidence interval -0.08 to $-0.05, \mathrm{P}<0.0001)$. Based on the annualised rate of exacerbations in the control subjects of 2.7 a year, this is a $29 \%$ reduction. The number needed to treat for one subject to have no exacerbation in the study period would be 6 . Days of illness also fell (weighted mean difference $-0.56,-0.77$ to $-0.35, \mathrm{P}<0.0001$ ). The number of subjects who had no exacerbations in the study period was greater in the mucolytic group (odds ratio 2.22, 95\% confidence interval 1.93 to 2.54, $\mathrm{P}<0.0001)$. There was no difference in lung function or in adverse events reported between treatments. Conclusions In chronic bronchitis and chronic obstructive pulmonary disease, treatment with mucolytics is associated with a reduction in acute exacerbations and days of illness. As these drugs have to be taken long term, they could be most useful in patients who have repeated, prolonged, or severe exacerbations of chronic obstructive pulmonary disease.
\end{abstract}

\section{Introduction}

At least half of smokers will develop chronic bronchitis, ${ }^{1}$ and up to $15 \%$ will develop limiting symptoms from chronic obstructive pulmonary disease. ${ }^{2}$ People with chronic bronchitis or chronic obstructive pulmonary disease may experience recurrent exacerbations with worsening symptoms or greater volume or purulence of sputum. These exacerbations contribute to morbidity and poorer health ${ }^{3}$ as well as to increased healthcare costs. ${ }^{4}$

Although these exacerbations can be treated with antibiotics or steroids, it would be useful to have other treatments that reduced the frequency and duration of acute exacerbations. Mucolytics increase the expectoration of sputum by reducing its viscosity or hypersecretion. ${ }^{5}$ Some are also antioxidants. ${ }^{6}$ These drugs might be of benefit in reducing exacerbations of chronic obstructive pulmonary disease. In some European countries, mucolytics are widely prescribed in the belief that they reduce the frequency of exacerbations or symptoms in patients with chronic bronchitis. However, in the United Kingdom and Australasia, mucolytics are used infrequently because they are perceived to be ineffective. Two oral mucolytics are currently available in the United Kingdom (carbocisteine and mecysteine $)^{7}$ and one in New Zealand (bromhexine). These drugs, however, are not funded in either country for adults with chronic obstructive pulmonary disease.

We conducted a systematic review to determine, firstly, if treatment with mucolytics reduced the frequency of exacerbations or days of illness in people with chronic bronchitis or chronic obstructive pulmonary disease and, secondly, to determine if mucolytics improve lung function or increase adverse events.

\section{Methods}

We did the first Cochrane systematic review on this topic in 1997 and updated it in 1999 using similar methods. ${ }^{8}$ We identified abstracts using the Cochrane Airways Group register. The register has been compiled from Medline, Embase, CINAHL, and hand searching of respiratory journals and meeting abstracts. We searched the register using the following terms: (chronic bronchitis or chronic obstructive pulmonary disease) and (mucolytics or $\mathrm{N}$-acetylcysteine or bromhexine or $S$-carboxymethylcysteine or ambroxol or sobrerol or iodinated glycerol).

From the abstracts of studies identified by this search strategy, we identified studies for full text review. In addition, we checked the reference lists of all the papers and reviews we obtained for any other relevant articles. We contacted researchers in the field and pharmaceutical companies asking for relevant material. We each independently selected trials for inclusion in the review. Disagreement over inclusion was resolved by discussion. Papers published in languages other than English were assessed with the help of four translators. When we needed more data or clarification, we wrote at least twice to authors and pharmaceutical companies.

\author{
Department of \\ Medicine, \\ University of \\ Auckland, Private \\ Bag 92019, \\ Auckland, \\ New Zealand \\ Phillippa J Poole \\ senior lecturer \\ Peter N Black \\ associate professor \\ Correspondence to: \\ P J Poole \\ p.poole@auckland. \\ ac.nz
}

BMJ 2001;322:1-6 
Details of studies included in systematic review

\begin{tabular}{|c|c|c|c|c|c|c|c|c|}
\hline Study & Country & $\begin{array}{l}\text { No of } \\
\text { patients }\end{array}$ & $\begin{array}{l}\text { Clinical criteria } \\
\text { (mean lung function) }\end{array}$ & $\begin{array}{l}\text { Mean age } \\
\text { (years) }\end{array}$ & $\begin{array}{l}\% \text { of } \\
\text { smokers }\end{array}$ & $\begin{array}{l}\text { Length of } \\
\text { study (months) }\end{array}$ & Intervention & $\begin{array}{l}\text { Quality } \\
\text { score }\end{array}$ \\
\hline Allegra $1996^{16}$ & Italy & 662 & Chronic bronchitis ( $\mathrm{FEV}_{1} 65 \%$ predicted) & 60.1 & 73 current & 6 & Carbocisteine lysine $2.7 \mathrm{~g}$ daily & 5 \\
\hline Babolini $1980^{17}$ & Italy & 744 & Chronic bronchitis ( $\left.\mathrm{FEV}_{1} 2.18 \mathrm{I}\right)$ & NA & 64.3 & 6 & Acetylcysteine $200 \mathrm{mg}$ twice daily & 4 \\
\hline Boman $1983^{18}$ & Sweden & 259 & $\begin{array}{l}\text { Chronic bronchitis } \\
\text { (FEV } 180 \% \text { predicted) }\end{array}$ & 51.9 & 100 & 6 & Acetylcysteine $200 \mathrm{mg}$ twice daily & 2 \\
\hline Bontognali $1991^{19}$ & Italy & 60 & Chronic bronchitis (NA) & 57 & NA & 3 & Citiolone $400 \mathrm{mg}$ twice daily & 3 \\
\hline Borgia $1981^{20}$ & Italy & 21 & Chronic bronchitis ( $\mathrm{FEV}_{1} 3.82 \mathrm{I}$ ) & 45.3 & NA & 6 & Acetylcysteine $200 \mathrm{mg}$ twice daily & 3 \\
\hline Castiglioni $1986^{21}$ & Italy & 706 & Chronic bronchitis ( $\mathrm{FEV}_{1} 73 \%$ predicted) & 56.5 & 73.5 & 3 & Sobrerol $300 \mathrm{mg}$ twice daily & 3 \\
\hline Cegla $1988^{22}$ & Italy & 180 & Chronic bronchitis (FEV $12.15 \mathrm{I})$ & 51.1 & 36 current & 24 & Ambroxol $75 \mathrm{mg}$ daily & 3 \\
\hline Cremonini $1986^{23}$ & Italy & 41 & Chronic bronchitis ( $\mathrm{FEV}_{1} 59 \%$ predicted) & 60.8 & NA & 3 & Letosteine $50 \mathrm{mg}$ thrice daily & 3 \\
\hline Ekberg-Jansson $1999^{24}$ & $\begin{array}{l}\text { Europe/ United } \\
\text { Kingdom }\end{array}$ & 637 & Chronic bronchitis ( $\mathrm{FEV}_{1} 73 \%$ predicted) & 58 & 100 & 6 & Isobutyrylcysteine $300 \mathrm{mg}$ twice daily & 3 \\
\hline Grassi $1994^{25}$ & Italy & 135 & Chronic bronchitis ( $\mathrm{FEV}_{1} 57 \%$ predicted) & 61.8 & 76 & 3 & Carbocisteine-sobrerol daily & 4 \\
\hline Grassi $1976^{26}$ & Italy & 80 & Chronic bronchitis (NA) & 60.9 & NA & 6 & Acetylcysteine $600 \mathrm{mg}$ three times/week & 3 \\
\hline Grillage $1985^{27}$ & $\begin{array}{l}\text { United } \\
\text { Kingdom }\end{array}$ & 109 & Chronic bronchitis (PEFR 232 l/min) & NA & NA & 6 & Carbocisteine $750 \mathrm{mg}$ thrice daily & 4 \\
\hline Jackson $1984^{29}$ & $\begin{array}{l}\text { United } \\
\text { Kingdom }\end{array}$ & 155 & Chronic bronchitis (NA) & 63 & 88 & 3 & Acetylcysteine $200 \mathrm{mg}$ thrice daily & 4 \\
\hline McGavin $1985^{30}$ & $\begin{array}{l}\text { United } \\
\text { Kingdom }\end{array}$ & 181 & Chronic bronchitis $\left(\mathrm{FEV}_{1} 0.86 \mathrm{I}\right)$ & 63.4 & 99 & 5 & Acetylcysteine $200 \mathrm{mg}$ thrice daily & 4 \\
\hline Meister 1986 & Germany & 252 & Chronic bronchitis (PEFR 303 l/min) & 57.2 & 88 & 6 & Acetylcysteine $300 \mathrm{mg}$ twice daily & 3 \\
\hline Meister $1999^{31}$ & Germany & 246 & Chronic bronchitis ( $\mathrm{FEV}_{1} 78 \%$ predicted) & 57.2 & 88 & 6 & Myrtol $300 \mathrm{mg}$ thrice daily & 4 \\
\hline Nowak 199911 & Europe & 313 & $\begin{array}{l}\text { Chronic obstructive pulmonary disease } \\
\text { (FEV } 60 \% \text { predicted) }\end{array}$ & 57 & NA & 8 & Acetylcysteine $600 \mathrm{mg}$ twice daily & 2 \\
\hline Olivieri $1987^{32}$ & Italy & 240 & Chronic bronchitis (NA) & NA & NA & 6 & Ambroxol 75 mg daily & 2 \\
\hline Parr $1987^{33}$ & $\begin{array}{l}\text { United } \\
\text { Kingdom }\end{array}$ & 526 & Chronic bronchitis (NA) & 63 & 86 & 6 & Acetylcysteine $200 \mathrm{mg}$ thrice daily & 4 \\
\hline Pela $1999^{34}$ & Italy & 169 & $\begin{array}{l}\text { Chronic obstructive pulmonary disease } \\
\text { (FEV } 158 \% \text { predicted) }\end{array}$ & 66 & $\begin{array}{c}28 \\
\text { currrent }\end{array}$ & 6 & Acetylcysteine $600 \mathrm{mg}$ daily & 3 \\
\hline Petty $1990^{35}$ & United States & 367 & Chronic bronchitis ( $\mathrm{FEV}_{1} 45 \%$ predicted) & 65 & NA & 2 & lodinated glycerol $60 \mathrm{mg}$ four times daily & 5 \\
\hline Rasmussen $1988^{36}$ & Sweden & 116 & Chronic bronchitis (PEFR $305 \mathrm{l} / \mathrm{min}$ ) & 58.9 & 100 & 6 & Acetylcysteine $300 \mathrm{mg}$ twice daily & 3 \\
\hline
\end{tabular}

$\mathrm{NA}=$ not available. $\mathrm{FEV}_{1}=$ forced expiratory volume in one second. PEFR=peak expiratory flow rate.

The included studies were randomised, double blind, placebo controlled studies of oral mucolytics taken regularly for at least two months. We excluded trials of inhaled mucolytics; combinations of mucolytics with antibiotics or bronchodilators; deoxyribonucleases; and proteases such as trypsin. Participants were adults $(>20$ years $)$ with chronic bronchitis or chronic obstructive pulmonary disease defined according to Medical Research Council, European Respiratory Society, or American or British Thoracic Society guidelines. Studies on people with asthma or cystic fibrosis were excluded.

The primary outcome measures were the number of acute exacerbations (including the number of participants with no exacerbations in the study period) and days of illness (defined as days in bed, days off work, or days when the participant was unable to undertake normal activities). Days taking antibiotics were also assessed. The secondary outcome measures were measures of lung function (including forced expiratory volume in one second, forced vital capacity, and peak expiratory flow rate) and adverse effects of treatment.

We used summary statistics rather than individual patient data. We assessed the quality of randomisation, blinding, and description of dropouts using the five point Jadad scale. ${ }^{9}$ Exacerbation rates and days of illness were calculated per patient per month by dividing the number of events by the number of participants and the number of months of the study. A fixed effects model was used. We analysed continuous data using the weighted mean difference (except for forced expiratory volume, percentage change in forced expiratory volume, and peak expiratory flow rate, which were combined by using a standardised mean difference because of the different scales used). The Peto odds ratio was used for dichotomous data. We used the Breslow-Day test for heterogeneity (variability in study results). ${ }^{10}$ The meta-analysis was done with Review Manager software (version 4.0 1999, Cochrane Collaboration and Update Software).

\section{Results}

We identified over 400 trials from the computer searches. After excluding studies that were clearly ineligible, we obtained the full text of 77 papers for independent scrutiny by the authors. In two unpublished studies, the information used was obtained from the abstract and from the pharmaceutical company ( $\mathrm{R}$ Meister, long term treatment with acetylcysteine retard, 1986). ${ }^{11}$ Twenty seven trials studied double blind placebo controlled treatment with an oral mucolytic drug for at least eight weeks. Four of these were excluded because they did not provide information on the primary outcome. ${ }^{12-15}$ The remaining 23 studies are included in the review (Meister). ${ }^{116-36}$ Twenty one studied people with chronic bronchitis and two studied people with chronic obstructive pulmonary disease (table). All 23 randomised controlled trials had a Jadad quality score of at least 2 out of 5 , and 20 had a score of 3 or more. $^{8}$

\section{Exacerbations}

Regular use of mucolytics was associated with a reduction of 0.07 exacerbations per patient a month $(95 \%$ confidence interval -0.08 to $-0.05, \mathrm{P}<0.0001$, fig). 


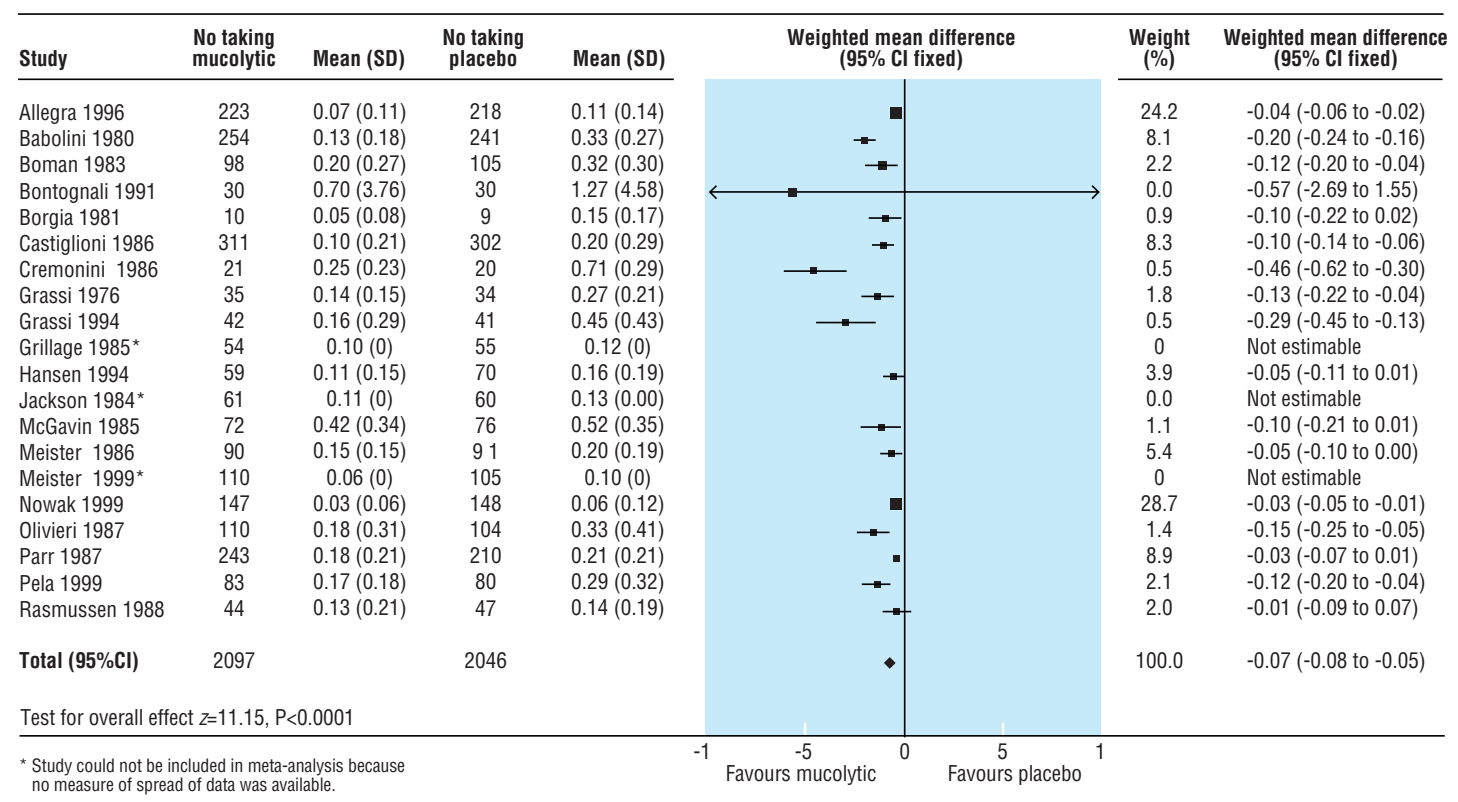

Fig 1 Mean (SD) number of exacerbations per subject per month, weighted mean difference, and 95\% confidence intervals

We were, however, unable to include data from a large American study ${ }^{35}$ in this analysis. This study reported no significant difference in exacerbation rates between iodinated glycerol and placebo, but the summary statistics were not available. An analysis of exacerbations that included this study and assumed that both treatment and control groups had the same exacerbation rates as the overall mean control exacerbation rate (0.23, SD 0.21 ) would have changed the effect size only slightly (to -0.062 a month). The odds ratio for having no exacerbation in the study period with mucolytic treatment compared with placebo was 2.22 (95\% confidence interval 1.93 to $2.54, \mathrm{P}<0.0001)$. Based on these numbers, the number needed to treat for one subject to remain free of exacerbations for the study period would be 6 . In contrast to the results seen for other drugs, there was no significant reduction in exacerbation rates with the thiol donor, isobutyrylcysteine. ${ }^{24}$

\section{Days of illness}

Mucolytic therapy significantly reduced the number of days of illness per subject per month by 0.56 days $(95 \%$ confidence interval -0.77 to $-0.35, \quad \mathrm{P}<0.0001)$.
Similarly, the number of days that subjects took antibiotics was reduced by 0.53 a month $(-0.76$ to -0.31 , $\mathrm{P}<0.0001)$.

\section{Lung function}

In the few studies that reported this outcome, the differences in both forced expiratory volume in one second and forced vital capacity between subjects receiving mucolytic drugs and placebo were small and not significant. We combined measurements of airflow (forced expiratory volume, percentage change in forced expiratory volume, peak expiratory flow rate and change in peak flow rate) using a standardised mean difference, to increase the power of the analysis, but this also showed no significant difference between treatment and placebo (fig 2).

\section{Adverse events}

Adverse events were usually mild and self limiting. The meta-analysis of total adverse events showed a significant effect in favour of mucolytic drugs (odds ratio $0.79,0.67$ to 0.93 ). However, this analysis does not include data from three studies that had more events

\begin{tabular}{|c|c|c|c|c|c|c|c|}
\hline Study & $\begin{array}{l}\text { No taking } \\
\text { mucolytic }\end{array}$ & Mean (SD) & $\begin{array}{l}\text { No taking } \\
\text { placebo }\end{array}$ & Mean (SD) & $\begin{array}{c}\text { Standardised mean difference } \\
(95 \% \mathrm{Cl} \text { fixed })\end{array}$ & $\begin{array}{c}\text { Weight } \\
(\%)\end{array}$ & $\begin{array}{c}\text { Standardised mean difference } \\
(95 \% \mathrm{Cl} \text { fixed })\end{array}$ \\
\hline Babolini 1980* & 234 & $2.25(0)$ & 224 & $2.23(0)$ & & 0 & Not estimable \\
\hline Bontognali 1991 & 30 & $2.49(0.79)$ & 30 & $2.14(0.84)$ & 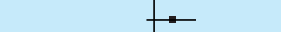 & 6.5 & $0.42(-0.09$ to -0.94$)$ \\
\hline Borgia 1981 & 10 & $3.54(0.60)$ & 9 & $3.05(1.14)$ & 1. & 2 & $0.52(-0.40$ to 1.44$)$ \\
\hline Cegla 1988 & 86 & $2.45(0.76)$ & 87 & $2.45(0.82)$ & + & 19.3 & $0.00(-0.30$ to 0.30$)$ \\
\hline Grillage 1985 & 54 & $271.00(127.00)$ & 55 & $252.00(92.00)$ & $\leftarrow$ & 12.1 & $0.17(-0.21$ to 0.55$)$ \\
\hline Olivieri 1987 & 104 & $1.94(0.71)$ & 94 & $1.88(0.57)$ & + & 22 & $0.09(-0.19$ to 0.37$)$ \\
\hline Pela 1999 & 83 & $1.58(0.63)$ & 80 & $1.50(0.56)$ & - & 18.1 & $0.13(-0.17$ to 0.44$)$ \\
\hline Total (95\%Cl) & 811 & & 818 & & $p$ & 100.0 & $0.07(-0.06$ to 0.20$)$ \\
\hline \multicolumn{8}{|c|}{ Test for overall effect $z=1.05, P=0.3$} \\
\hline
\end{tabular}

Fig 2 Lung function at end of study period 
than subjects and could therefore not be analysed using the Peto odds ratio method. If these three studies are included, there were 1890 adverse events in 2450 subjects taking mucolytic drugs and 1882 events in 2453 subjects taking placebo (mean of 0.77 events per subject in both groups). There is, therefore, probably no difference between mucolytic and placebo treatments in terms of the total number of adverse events.

\section{Discussion}

Our systematic review shows that mucolytic drugs have a modest but significant effect on exacerbation rates in people with chronic bronchitis and chronic obstructive pulmonary disease. The reduction of 0.07 exacerbations per month is $29 \%$ lower than the rate in the control group. On the basis of the annualised exacerbation rate (weighted for study size) of 2.7 per patient per year in the control group, mucolytic treatment was associated with a reduction of 0.79 exacerbations per patient per year. This approach, however, tends to overestimate the annual number of exacerbations as more exacerbations occur during winter, when most of these studies were done.

\section{Robustness of results}

We found significant heterogeneity in the precision of the measure of the effect size among the studies in this analysis $(\mathrm{P}<0.0001)$. To explore possible reasons for this, we performed subgroup analysis using previously determined criteria. These criteria were the baseline forced expiratory volume in one second (as \% predicted), the type and dose of mucolytic, whether subjects were included because they had a history of exacerbations, the duration of treatment, and the country in which the study was conducted. Significant heterogeneity was eliminated in the analysis of the two studies in which forced expiratory volume was less than $50 \%$ predicted and in the analysis of the 11 studies not conducted in Italy. Most of the heterogeneity is not explained.

Despite this, we consider that the finding that mucolytic drugs reduce the exacerbation rate is robust. Fewer exacerbations with mucolytic drugs were seen in all 20 studies, and there was internal consistency between the outcomes. In addition, there was no significant heterogeneity for the outcome "subjects with no exacerbations in the study period." Subjects who received mucolytic drugs were twice as likely to have no exacerbation in the study than if they had received placebo. The effect of mucolytics on days of illness (0.56 days less per subject per month) was greater than the effect on number of exacerbations, but is roughly what would be expected clinically as an exacerbation usually lasts for several days. This finding was based on six studies, although there was some heterogeneity between them $(\mathrm{P}=0.0034)$. However, there were four other studies with mean values reported (but no SD), and these all showed a reduction in days of illness with mucolytics that was between 0.3 and 3.9 days per subject per month. Subjects took antibiotics for less time as well. These findings suggest that the exacerbations that do occur are either less serious or less prolonged.

\section{Hospital admission rates}

None of the studies reported the effect of treatment with mucolytics on hospital admission for chronic obstructive pulmonary disease. It is important that this outcome is included in future studies as it contributes greatly to the costs of treating severe chronic obstructive pulmonary disease. Studies of other types of treatment for chronic obstructive pulmonary disease have shown an effect on hospital admissions. A recent randomised controlled trial has shown that pulmonary rehabilitation reduces hospital bed days, mainly by reducing length of stay. ${ }^{37}$ An immunomodulatory agent $\mathrm{OM}-85 \mathrm{BV}^{38}$ has been shown to reduce the number of hospital admissions, even though it did not affect the number of exacerbations.

\section{Definition of disease}

Most of the studies were conducted many years ago on patients with chronic bronchitis, and most used the Medical Research Council definition "the presence of cough and sputum for three or more months in two consecutive years." More recent studies have focused on patients with chronic obstructive pulmonary disease-that is, those with irreversible airflow obstruction. Nevertheless, in the earlier chronic bronchitis studies the percentage of smokers was high and many patients had evidence of some airflow limitation. It is likely, therefore, that today many would be defined as having chronic obstructive pulmonary disease (see table). The reduction in exacerbations seen with mucolytics in the two studies in chronic obstructive pulmonary disease was at least as large as that seen in subjects with chronic bronchitis. ${ }^{11}{ }^{34}$ Thus, we feel justified in including studies of both chronic bronchitis and chronic obstructive pulmonary disease in this review.

\section{How do the drugs work?}

Although the mechanism(s) by which mucolytic drugs reduce exacerbation rates and days of illness cannot be determined from this review, some hypotheses may be generated. Acetylcysteine was used in 12 of the studies. Although this drug has mucolytic and antioxidant effects, the reduction in exacerbation rates with this drug was virtually identical to that seen with the other mucolytics, when they were examined as a group. Isobutyrylcysteine is a derivative of acetylcysteine, and was promoted as an antioxidant thiol donor, yet the only study of this drug found no effect on exacerbations. ${ }^{24}$ This suggests that the beneficial effect of acetylcysteine is not due to its actions as a thiol donor. However, acetylcysteine may still act as an antioxidant in other ways.

\section{Is treatment justified?}

Clinicians and patients will need to judge for themselves whether the reductions in exacerbation rate and days of illness seen with mucolytic drugs are large enough to warrant daily treatment for at least three to six months a year. At recommended doses, the available mucolytics in United Kingdom cost over $£ 200$ a year. A short course of amoxicillin or prednisolone for one infective exacerbation costs around $£ 2 .{ }^{7}$ In most of the studies, subjects had mild chronic obstructive pulmonary disease, defined by their degree of airways obstruction. A recent analysis of the cost effectiveness of acetylcysteine in chronic bronchitis suggested that the point at which the costs of 


\section{What is already know on this topic}

Mucolytic drugs have properties that may be beneficial in chronic obstructive pulmonary disease

These drugs are not prescribed in the United Kingdom and Australasia, although they are widely used in many other countries

Drugs that reduce exacerbations may reduce the morbidity and healthcare costs associated with progressively severe disease

\section{What this study adds}

Regular use of mucolytic drugs for at least two months significantly reduces exacerbations and days of illness compared with placebo in patients with chronic bronchitis and chronic obstructive pulmonary disease

Exacerbations that do occur may not be as severe, and the benefit may be greater in those with more severe disease

Reductions are modest and treatment may not be cost effective

treatment and non-treatment are equal was 0.6 fewer exacerbations per six months. ${ }^{39}$ In our review, exacerbations decreased by less than this $(0.4$ per six months). However, evidence from the two studies in patients with a mean forced expiratory volume less than $50 \%$ of predicted showed a reduction in the exacerbation rate of 0.13 per patient per month $(0.8$ per six months), suggesting that the benefit may be greater in those with more severe chronic obstructive pulmonary disease. Patients who have frequent or prolonged exacerbations or those who are repeatedly admitted to hospital with exacerbations of chronic obstructive pulmonary disease may also benefit more.

The reduction in the exacerbation rate per month was greater for the studies that lasted three months or less $(0.13$ per subject) than for those that lasted over three months ( 0.06 per subject). This suggests that the full benefit is seen early and does not increase subsequently. There was no evidence that mucolytics affected lung function in these studies or that they are unsafe.

Future randomised controlled trials should examine the value of mucolytic drugs in patients who have repeated, prolonged, or severe exacerbations or who are repeatedly admitted to hospital with exacerbations of chronic obstructive pulmonary disease. Use of mucolytics in acute exacerbations of chronic obstructive pulmonary disease should also be studied. All of these studies should include a measure of use of healthcare resources.

Paul Jones, Peter Gibson, Chris Cates, Anna Bara, and Karen Blackhall of the Cochrane Airways Group provided editorial and technical support. Silvana Campanella, Ruth Black, Klaus Lehnert, and Daniela Screnci translated for us. Further data were provided by Dompe farmaceutici, Zambon Group, and Douglas Pharmaceuticals.

Contributors: PNB initiated the protocol development. PJP and PNB collaborated on every step of both the first review and the update including protocol design, comparisons, data extrac- tion, analysis, interpretation of results, and writing of the paper.

$\mathrm{PJP}$ is the guarantor.

Funding: None.

Competing interests: None declared.

1 Redline S. Epidemiology of COPD. In: Cherniack N, ed. Chronic obstructive pulmonary disease. Philadelphia: Saunders, 1991.

2 Fletcher C, Peto R, Tinker C, Speizer FE. The natural history of chronic bronchitis and emphysema: an eight year study of early chronic lung disease in working men in London. Oxford: Oxford University Press, 1976.

3 Seemungal TA, Donaldson GC, Paul EA, Bestall JC, Jefferies DJ, Wedzicha JA. Effect of exacerbation on quality of life in patients with chronic obstructive pulmonary disease. Am J Respir Crit Care Med 1998;157:141822

4 Feinleib M, Rosenberg HM, Collins JG, Delozier JE, Pokras R, Chevarley FM. Trends in COPD morbidity and mortality in the United States. $A m$ Rev Respir Dis 1989;140:S9-18.

5 Del Donno M, Olivieri D. Mucoactive drugs in the management of chronic obstructive pulmonary disease. Momaldi Arch Chest Dis 1998:53:714-9.

6 Rahman I, Skwarska E, MacNee W. Attenuation of oxidant/antioxidant imbalance during treatment of exacerbations of chronic obstructive pulmonary disease. Thorax 1997;52:565-8.

7 British Medical Association, Royal Pharmaceutical Society of Great Britain. British National Formulary. London: BMA, RPS, 2000. (No 40.)

8 Poole PJ, Black PN. Mucolytics in chronic bronchitis. Cochrane Database Syst Rev 2000;(2):CD001287.

9 Moher D, Jadad AR, Tugwell P. Assessing the quality of randomized controlled trials. Current issues and future directions. Int J Technol Asses. Health Care 1996;12:195-208.

10 Fleiss JL. The statistical basis of meta analysis. Stat Meth Med Res 1993;2:121-45.

11 Nowak D, Carati L, Pirozynski M. Long-term administration of $\mathrm{N}$-acetylcysteine reduces the number of acute exacerbation episodes in subjects with chronic obstructive pulmonary disease: report of the BREATHE study. Eur Respir J 1999;14:381-2s.

12 Edwards GF, Steel AE, Scott JK, Jordan JW. S-carboxymethylcysteine in the fluidification of sputum and treatment of chronic airway obstruction Chest 1976;70:506-13.

13 Maesen FP, Brombacher PJ. Treatment of chronic bronchitis with oral acetylcysteine, a double-blind study. Eur J Respir Dis 1980;61(suppl 111): 110

14 Rubin BK, Ramirez O, Ohar JA. Iodinated glycerol has no effect on pulmonary function, symptom score, or sputum properties in patients with stable chronic bronchitis. Chest 1996;109:348-52.

15 Christensen SB, Kjer J, Ryskjaer S, Arseth-Hansen P, Christensen F. Mucolytic treatment of chronic bronchitis during two winter periods. Scand J Respir Dis 1971;52:48-57.

16 Allegra L, Cordaro CI, Grassi CTI. Prevention of acute exacerbations of chronic obstructive bronchitis with carbocysteine lysine salt monohydrate: a multicenter, double-blind, placebo-controlled trial. Respiration 1996;63:174-80

17 Multicenter Study Group. Long-term oral acetylcysteine in chronic bronchitis. A double-blind controlled study. Eur J Respir Dis 1980;61:93-108.

18 Boman G, Backer U, Larsson S, Melander B, Wahlander L. Oral acetylcysteine reduces exacerbation rate in chronic bronchitis; report of a trial organized by the Swedish Society for Pulmonary Diseases. Eur J Respir Dis 1983;64:405-15.

19 Bontognali E. Clinical effectiveness and tolerance of cithiolone in the prophylaxis of acute infective exacerbations in patients suffering from chronic bronchitis. Acta Therapeutica 1991;17:155-62.

20 Borgia M, Sepe N, Ori-Belometti M, Borgia R. Confronto tra acetilcisteina e placebo nel trattamento a lungo termine della bronchite cronica Gaz Med Ital 1981:140:467-72.

21 Castiglioni CL, Gramolini C. Effect of long-term treatment with sobrero on the exacerbations of chronic bronchitis. Respiration 1986;50:202-17.

22 Cegla UH. Langzeittherapie uber 2 jahre mit ambroxol (Mucosolvan) retardkapseln bei patienten mit chronischer bronchitis. Ergebnisse eine doppelblinstudie an 180 patienten. Prax Klin Pneumol 1988;42:715-21.

23 Cremonini C, Spada E, Cellini F, Cioni R, Giovannini M, Perri G, et al. farmaci attivi sul muco nel trattamento di fondo della bronchite cronica. Clin Ther 1986;116:121-9.

24 Ekberg-Jansson A, Larson M, MacNee W, Tunek A, Wahlgren L, Wouters $\mathrm{EF}$, et al. N-isobutyrylcysteine, a donor of systemic thiols, does not reduce the exacerbation rate in chronic bronchitis. Eur Respir J 1999;13:829-34

25 Grassi C, Casali L, Ciaccia A, Marchioni CF, Pivirotto F, Rimoldi R, et al Terapia intervallare con l'associazione carbocisteina-sobrerolo nella profilassi delle riacutizzazioni della bronchite cronica. Ital J Chest Dis 1994;48:17-26.

26 Grassi C, Morandini GC. A controlled trial of intermittent oral acetylcysteine in the long-term treatment of chronic bronchitis. Eur J Clin Pharmacol 1976;9:393-6.

27 Grillage M, Barnard-Jones K. Long-term oral carbocisteine therapy in patients with chronic bronchitis. A double blind trial with placebo control. Br J Clin Pract 1985 Oct:395-8.

28 Hansen NC, Skriver A, Brorsen-Riis L, Bolsov S, Evald T, Maltbaek N, et al. Orally administered $\mathrm{N}$-acetylcysteine may improve general well-being in patients with mild chronic bronchitis. Respir Med 1994;88:531-5.

29 Jackson IM, Barnes J, Cooksey P. Efficacy and tolerability of ora acetylcysteine (fabrol) in chronic bronchitis: a double-blind placebo controlled trial.J Int Med Res 1984;12:198-206.

30 British Thoracic Society Research Committee. Oral N-acetylcysteine and exacerbation rates in patients with chronic bronchitis and severe airways obstruction. Thorax 1985;40:832-5. 
31 Meister R, Wittig T, Beuscher N, de Mey C. Efficacy and tolerability of myrtol standardized in long-term treatment of chronic bronchitis. A double-blind, placebo-controlled study. Arzneimittelforschung 1999;49: 351-8.

32 Olivieri D, Zavattini G, Tomasini G, Daniotti S, Bonsignore G, Ferrara G, et al. Ambroxol for the prevention of chronic bronchitis exacerbations: long-term multicenter trial. Respiration 1987;51:42-51.

33 Parr GD, Huitson A. Oral fabrol (oral n-acetyl-cysteine) in chronic bronchitis. Br J Dis Chest 1987;81:341-8.

34 Pela R, Calcagni AM, Subiaco S, Isidori P, Tubaldi A, Sanguinetti CM. $\mathrm{N}$-acetylcysteine reduces the exacerbation rate in patients with moderate to severe COPD. Respiration 1999;66:495-500.

35 Petty TL. The national mucolytic study: results of a randomized, doubleblind, placebo-controlled study of iodinated glycerol in chronic obstructive bronchitis. Chest 1990;97:75-83.
36 Rasmussen JB, Glennow C. Reduction in days of illness after long-term treatment with $\mathrm{N}$-acetylcysteine controlled-release tablets in patients with chronic bronchitis. Eur Respir J 1988;1:355.

37 Griffiths TL, Burr ML, Campbell IA, Lewis-Jenkins V, Mullins J, Shiels K, et al. Results at 1 year of outpatient multidisciplinary rehabilitation: a randomised controlled trial. Lancet 2000;355:362-8.

38 Collet JP, Shapiro P, Ernst P, Renzi T, Ducruet T, Robinson A. Effects of an immunostimulating agent on exacerbations and hospitalization in patients with chronic obstructive pulmonary disease. Am J Respir Crit Care Med 1997;156:1719-24

39 Grandjean EM, Berthert P, Ruffman R, Leuenberger P. Cost-effectiveness analysis of oral $\mathrm{N}$-acetyl cysteine as a preventive treatment in chronic bronchitis. Pharmacol Res 2000;42:39-50.

(Accepted 28 February 2001) 